
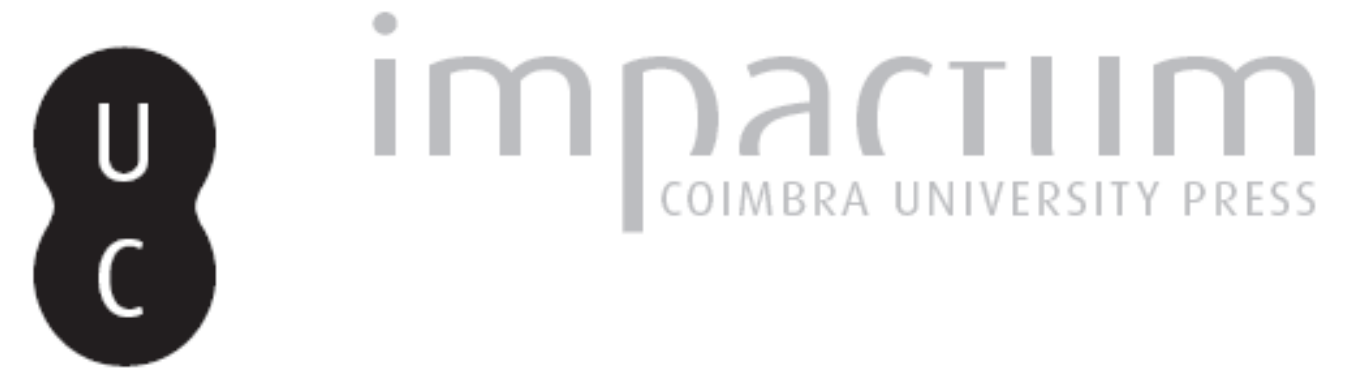

Caminhos-de-ferro da Beira (1845-1893)

Autor(es): $\quad$ Pereira, Hugo Silveira

Publicado por: Centro de História da Sociedade e da Cultura

URL persistente:

URI:http://hdl.handle.net/10316.2/39485

DOI:

DOI:http://dx.doi.org/10.14195/1645-2259_11_11

Accessed : $\quad$ 26-Apr-2023 07:44:51

A navegação consulta e descarregamento dos títulos inseridos nas Bibliotecas Digitais UC Digitalis, UC Pombalina e UC Impactum, pressupõem a aceitação plena e sem reservas dos Termos e Condições de Uso destas Bibliotecas Digitais, disponíveis em https://digitalis.uc.pt/pt-pt/termos.

Conforme exposto nos referidos Termos e Condições de Uso, o descarregamento de títulos de acesso restrito requer uma licença válida de autorização devendo o utilizador aceder ao(s) documento(s) a partir de um endereço de IP da instituição detentora da supramencionada licença.

Ao utilizador é apenas permitido o descarregamento para uso pessoal, pelo que o emprego do(s) título(s) descarregado(s) para outro fim, designadamente comercial, carece de autorização do respetivo autor ou editor da obra.

Na medida em que todas as obras da UC Digitalis se encontram protegidas pelo Código do Direito de Autor e Direitos Conexos e demais legislação aplicável, toda a cópia, parcial ou total, deste documento, nos casos em que é legalmente admitida, deverá conter ou fazer-se acompanhar por este aviso. 


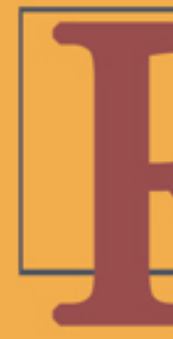

\section{evista de História} da Sociedade e da Cultura

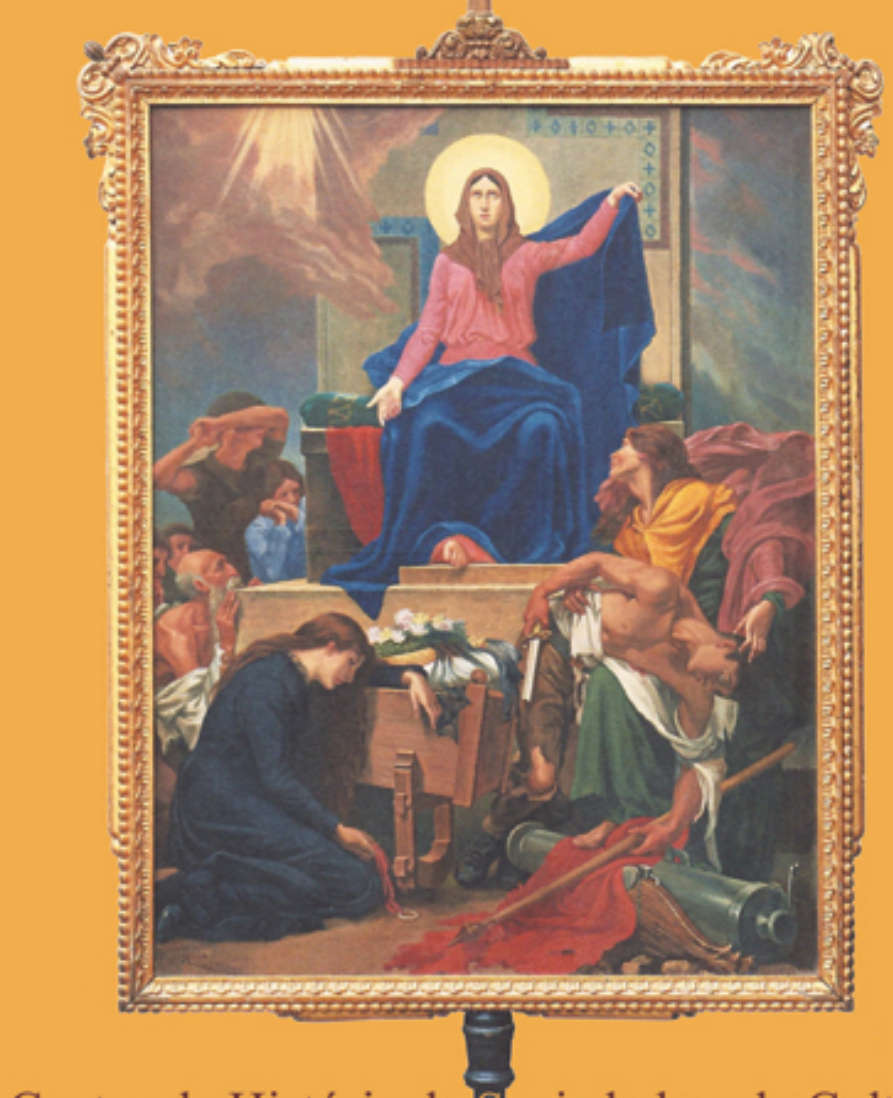

Centro de História da Sociedade e da Cultura Universidade de Coimbra 


\title{
Caminhos-de-ferro da Beira (1845-1893)
}

\author{
Hugo Silveira Pereira \\ CITCEM - FLUP \\ Financiado por Fundos Nacionais através da FCT - Fundação para a Ciência e \\ a Tecnologia no âmbito do projecto PEst-OE/HIS/UI4059/2011 \\ Texto recebido em/ Text submitted on: 15/02/2011 \\ Texto aprovado em/ Text approved on: 01/08/2011
}

\section{Resumo/Abstract:}

Na segunda metade de Oitocentos, Portugal reuniu as condições políticas e económicas para empreender a construção de caminhos-de-ferro, tal como vinham fazendo outros países. O objectivo era ligar Lisboa à Europa, integrando a economia nacional no grande movimento comercial que então se verificava. Simultaneamente, esperava-se o desenvolvimento das zonas nacionais então atravessadas pelas ferrovias. A passagem pela Beira parecia incontornável dada a posição geográfica de Portugal, mas os comboios só muito tardiamente circulariam nesta província.

O texto que se segue (que deriva de um projecto de doutoramento actualmente em curso sobre a política ferroviária nacional entre 1845 e 1900) pretende explicitar como se escalonou a construção de vias-férreas na Beira, desde a feitura de estudos, até à execução das obras. Nesse sentido, analisaram-se relatórios publicados no Boletim do Ministério das Obras Públicas (BMOP) e na Revista de Obras Públicas e Minas (ROPM) ou redigidos pelo Conselho Superior (CSOP) e a sua herdeira Junta Consultiva (JCOP), à guarda do Arquivo Histórico do Ministério das Obras Públicas (AHMOP); os debates parlamentares; e, uma vez que a ligação a Espanha era incontornável, relatórios de engenheiros espanhóis, alguns registos do Arquivo Histórico-Diplomático (AHD) e as opiniões das instâncias militares.

In the second half of the XIX century Portugal had achieved the political and economical conditions to undertake the construction of the railway, as it was happening for some time in a vast part of the Europe. The purpose was to link Lisbon to Europe, so that the national economy could take part in the big commercial movement that was going on in Europe. At the same time the development of the national territory crossed by the railway was expected. The crossing of Beira seemed undoubtedly in view of the geographical situation of Portugal, but only very lately the trains would run across this region.

This paper is a product of a doctorship project in progress concerning the national railway politics from 1845 to 1900 . It intends to explain the stages of the construction of the railway in Beira region; from the development of studies up to the accomplishment of the works, including the parliamentary debates. Therefore this investigation went through the reports published in the Boletim do Ministério das Obras Públicas (BMOP) and in the Revista de Obras Públicas e Minas as well as the reports done by the Conselho Superior (CSOP) and its successor the Junta Consultiva (JCOP) kept by the Arquivo Histórico do Ministério das Obras Públicas, and the parliamentary debates. As the link to Spain was obligatory, reports made by Spanish engineers, some records belonging to the Arquivo Histórico-Militar (AHD) and also the opinions of the military instance were also examined.

Palavras chave/Keywords:

Caminho-de-ferro; Transportes; Beira.

Railway; Transports; Beira. 


\section{A origem da questão}

Quando Portugal ponderou construir caminhos-de-ferro, o principal objectivo era ligar o porto de Lisboa à Europa. Simultaneamente, revolucionava-se o sistema de transportes coevo, caracterizado por um enorme arcaísmo. Antes das ferrovias e das estradas que duravam mais do que um Inverno, "os eixos fundamentais dos transportes portugueses eram constituídos pela cabotagem na orla maritima e pela navegação fluvial". Em termos de comunicação interna, predominavam fracas estradas, barcas de travessia fluvial ou a ausência de obstáculos geográficos, cruzados por almocreves, recoveiros, carros movidos a tracção animal e... salteadores ${ }^{2}$. A excepção residia em zonas onde houvesse algum interesse imediato a explorar e que fossem servidas por rios. Contudo, em grande parte destes rios a navegabilidade era limitada, além de que muitas regiões (30 a 40\% do território continental ${ }^{3}$ ) encontravam-se afastadas de leitos navegáveis. Em suma, "viajar em Portugal era arriscado, moroso, incómodo e, porque dispendioso, reservado a poucos", depositadas no caminho-de-ferro. A grande expectativa era fazer de Lisboa o cais da Europa ${ }^{5}$, a grande plataforma de ligação entre o Velho Continente e a América e este foi o principal objectivo da política ferroviária nacional até ao início da década de 1880.

Assim se procedeu no tempo de Costa Cabral, com o engenheiro Du Pré6; assim procedeu Fontes quando dá preferência a uma ligação a Espanha (lei de 18-8-1853). Quanto à forma como essa ligação se faria, poucas

1 SERRÃO, Joel - Temas Oitocentistas II. Lisboa: Portugália, 1962, 269.

2 GUILLEMOIS, Isabelle - Les transports au Portugal au XIX siècle (de 1843 à 1899) à travers les Viagens na Minha Terra de Almeida Garrett et As Farpas de Ramalho Ortigão. Bordéus: Université Michel de Montaigne, 1995.

3 JUSTINO, David - A formação do espaço económico nacional. Lisboa: Vega, 1988$-1989,189$.

4 ALEGRIA, Maria Fernanda-A organização dos transportes em Portugal (1850-1910). Lisboa: Centro de Estudos Geográficos, 1990, 104.

5 RAMOS, Paulo - Os caminhos de ferro e o cais da Europa in GOMES, Gilberto e SERRÃO, Joel (coord.) - O Caminho de ferro em Portugal de 1856 a 1996. [S.1.]: CP, 1996, 24-33.

6 DU PRÉ, José Luís Vítor - Relatorio ácerca da direcção que mais convirá dar ao caminho de ferro que ha de ir das margens do Tejo á fronteira de Hespanha. Revista de Engenharia Militar. 10 (1905), 244-260. 
eram as certezas, dada a falta de conhecimento estatístico e orográfico do País ${ }^{7}$. Se era óbvio que a ligação se deveria fazer pela fronteira Este, já o ponto fronteiriço a atravessar e a directriz em Portugal eram questões mais complexas.

Apesar de nas ocasiões indicadas a escolha ter recaído sobre Badajoz, aventou-se a possibilidade de uma linha que atravessasse a Beira ou pelo vale do Tejo ou pelo Norte da província, segundo propostas de Bacon, Pereira de Sousa, Albino de Figueiredo, Sousa Brandão, Gromicho Couceiro e Nunes de Aguiar ${ }^{8}$.

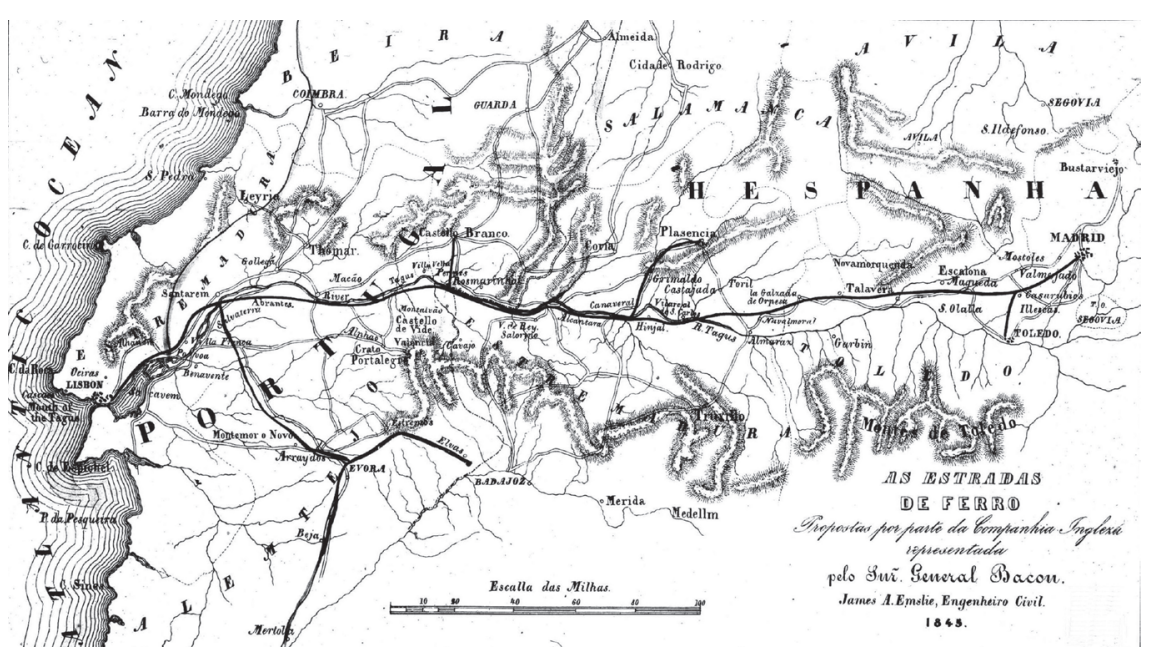

Proposta da companhia inglesa representada por Bacon ${ }^{9}$

No entanto as previstas dificuldades e custos de construção, a menor extensão da linha de Elvas e sua ligação a Madrid, a percepcionada maior riqueza da zona atravessada e a falta de vontade técnica e política

7 DIAS, Helena - Os primórdios da Moderna Cartografia Militar em Portugal. Revista da Faculdade de Letras. 5, 24 (1999) 51. SOUSA, Fernando de - História da estatística em Portugal. Lisboa: INE, 1995.

8 ASSOCIAÇÃO DOS ENGENHEIROS CIVIS PORTUGUESES (AECP) - O caminho de ferro da Beira. ROPM. 4 (1873), 38, 47-53. ALMEIDA, Albino de Figueiredo e - Vias de communicação. Lisboa: Revista Popular, 1851, 21-23. AHMOP. CSOP. Livro 1, 291-301.

9 AHMOP. Mapas. D-6-3-A. 
de Espanha em continuar tal via impediram a realização deste projecto no imediato ${ }^{10}$.

Após o fracasso da Companhia Central Peninsular (CCP) na construção da linha de Lisboa a Santarém (1855) e na iminência de o contrato com Morton Peto (assinado em 1857 para a linha do Norte) conhecer o mesmo destino, equacionou-se a possibilidade de se construir a linha da Beira ${ }^{11}$, tendo-se ordenado alguns estudos desde 1857.

Nunes de Aguiar (1857) previa ligações pelas duas margens do Tejo, preferindo a margem esquerda com ligação a Badajoz, por permitir a construção de uma ferrovia em melhores condições de tracção (em termos de raios das curvas e de declives das rampas), embora colocasse Madrid mais longe de Lisboa do que de Cádiz, excepto se se alterasse a directriz das linhas em Espanha ${ }^{12}$.

Mais a Norte, Conrado Chelmicki (1858) previa uma linha entre Coimbra e Almeida. Ligava Lisboa mais rapidamente a França e era uma linha, na sua opinião, com poucas obras de arte, que passava por terrenos ricos em materiais de construção e que permitiria o prolongamento até à Figueira ${ }^{13}$.

O terceiro, de Sousa Brandão (Julho de 1859), era mais consistente e anunciava a linha como a base de todos os caminhos-de-ferro nacionais (seguia com a linha do Norte até Miranda do Corvo, divergindo depois por Lousã, Seia, Celorico e Almeida) e a forma mais rápida para Lisboa se ligar ao resto do País e à Europa. Internamente atravessava zonas com tais interesses económicos que só por si a justificavam. A alternativa pela margem direita do Mondego por Pampilhosa, Santa Comba e Celorico

${ }^{10}$ Biblioteca da Assembleia da República (BAR). Caminhos de ferro. Pareceres parlamentares de 1845 a 1884. [Parecer da comissão encarregada de apreciar o contrato Hislop]. GUERRA, Manuel José Júlio et al. - Relatório da Commissão incumbida de propor o ponto por onde deve passar o caminho de ferro de Lisboa a Madrid. BMOP. 1855, 1, 3-8. WAIS, Francisco - Historia de los Ferrocarriles Españoles. Madrid: Nacional, 1974, 144-147 e 200-205.

${ }^{11}$ PEREIRA, Hugo Silveira - Caminhos-de-ferro nos debates parlamentares (1845-1860). Porto: FLUP, 2008, 131, 133 e 158.

${ }^{12}$ AGUIAR, Joaquim Nunes de - Relatorio sobre o reconhecimento nas duas margens do Tejo. BMOP. 1859, 12, 613-617.

${ }^{13}$ CHELMICKI, José Carlos Conrado - Relatorio sobre o traçado de um caminho de ferro pela Beira. BMOP. 1860, 1, 71-74. 
era descartada por ser demasiado difícil e não possibilitar condições de tracção favoráveis ${ }^{14}$.

Finalmente, Gromicho Couceiro (Setembro de 1859) fixava uma directriz desde a Mealhada, por Mangualde, Trancoso e Vilar Formoso. Seria uma linha de extrema dificuldade, devido ao acidentado do terreno, que obrigaria a grandes despesas na construção e na exploração ${ }^{15}$.

A alternativa por Elvas tinha também duas prospecções, além das de Du Pré e de Nunes de Aguiar: a de Thomas Rumball (1855), engenheiro da CCP, e a de Watier (1856) que aportara a Portugal na sequência dos falhanços daquela companhia e de Peto. Ambos optavam pela linha que seguindo o vale do Tejo atravessasse o rio entre Constância e Chamusca e seguisse para Badajoz.

Na câmara alta do parlamento surgiam alguns alvitres favoráveis à via pela Beira. Para o visconde da Luz (director-geral das Obras Públicas), esta não invalidava uma outra por Badajoz, mas aquela serviria preferencialmente o tráfego de passageiros e esta o de mercadorias. Para o visconde de Sá da Bandeira era a solução mais curta em termos de traçado entre as duas capitais ibéricas ${ }^{16}$.

Apesar de a linha da Beira reunir a predilecção de engenheiros e de alguns parlamentares, seria a linha de Watier a escolhida, pela razão de ter sido a que mereceu a atenção da iniciativa privada. A construção pelo Estado só era encarada em casos excepcionais, pelo que a aparição de José de Salamanca, que era apoiado pela empresa espanhola MZA que só tinha interesse numa ligação por Badajoz, pois detinha a concessão entre este cidade e Ciudad Real, facilitou a escolha ${ }^{17}$. Por outro lado, a vontade política de Madrid em

${ }^{14}$ BRANDÃO, Francisco Maria de Sousa-Relatorio sobre o reconhecimento do caminho de ferro pela Beira. BMOP. 1860, 3, 261-280. VIEIRA, Boaventura José - Caminho de ferro da Beira Alta. ROPM. 6 (1875), 63, 116-153.

${ }^{15}$ COUCEIRO, José Anselmo Gromicho - Relatorio sobre o resultado do reconhecimento do terreno entre o caminho de ferro do Norte e a fronteira de Leste. BMOP. 1860, 1, 74-75.

${ }^{16}$ Diário do Governo. Sessão da câmara dos Pares de 26-3-1859, 564-565. Arquivo Histórico Militar (AHM). Arquivo Particular de Sá da Bandeira (APSB). Vias ferreas projectadas entre Lisboa e Valladolid, e Lisboa e Madrid, e de Valladolid à fronteira de França. Div 3/18/9/16/16.

17 VIEIRA, António Lopes - The role of Britain and France in the finance of portuguese railways 1850-1890. Leicester: Leicester University, 1983, 269 e ss. 


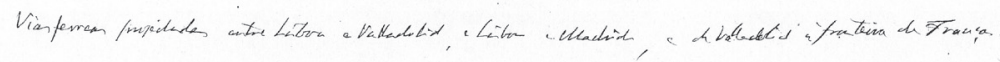
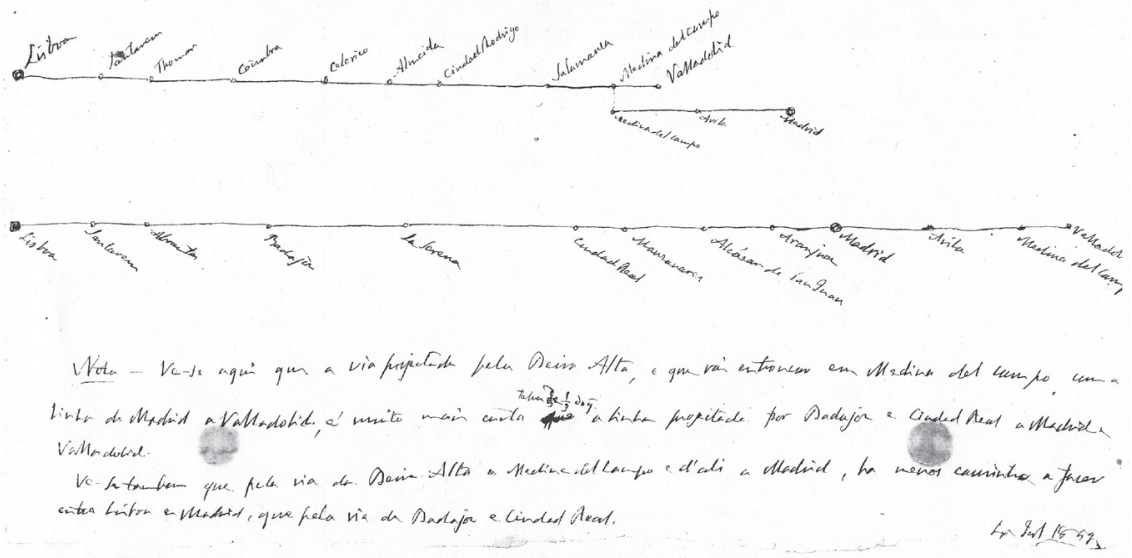

Comparação de traçados por Sá da Bandeira

continuar uma linha que atravessasse a fronteira entre o Tejo e o Douro era praticamente nula ${ }^{18}$, pois nada lucrava em beneficiar o porto de Lisboa.

\section{De novo enjeitada}

Ainda a linha de Leste estava em construção e já Belchior Garcês, engenheiro e deputado do Partido Histórico, lamentava a sua escolha em prejuízo da linha da Beira por parte do governo regenerador ${ }^{19}$. Todavia em Espanha apenas os responsáveis pelos estudos das ferrovias de Salamanca a Portugal e no Oeste se mostravam interessados nesta ligação ${ }^{20}$. Se dependesse apenas do CSOP, o caminho-de-ferro avançava, pois era uma forma de evitar a estagnação da província que nada retiraria das linhas de Norte e Leste, de ligar o País mais rapidamente a França e de servir de base a outros caminhos-

\footnotetext{
${ }^{18}$ BMOP. 1862, 1, 43-45.

${ }^{19}$ Diário de Lisboa (DL). Sessão da câmara dos deputados de 7-6-1862, 1565.

${ }^{20}$ AHMOP. CSOP. Livro 19, 533-535.
} 
de-ferro em direcção a Trás-os-Montes ${ }^{21}$. Porém, o esforço que então se fazia com as vias de Norte e Leste e com os prolongamentos de Vendas Novas a Évora e Beja (subsidiadas pelo Estado) impedia a construção de outras grandes linhas. O próprio CSOP preferia que o governo se concentrasse na conclusão das obras em curso e investisse em estradas ${ }^{22}$.

À medida que essas obras se aproximavam do seu fim, tornava-se ainda mais clara a necessidade de uma alternativa que evitando Madrid ligasse Lisboa directamente a França. No parlamento, rapidamente se iniciaram as movimentações para a colocar na lista de prioridades. Em 1864, vários deputados beirões procuram convencer o governo da necessidade da verdadeira via internacional, lembrando como a Beira era a província mais povoada de Portugal e dona de riquezas encravadas pela falta de comunicações ${ }^{23}$. Em 12-4-1864 Tomás Ribeiro reúne apoios no hemiciclo (entre os seus colegas regeneradores e beirões e com os transmontanos de outros quadrantes políticos que viam na linha o primeiro passo para servir de vias-férreas as suas zonas de influência) e apresenta um projecto de lei que dava ao caminho-de-ferro da Beira Alta preferência sobre qualquer outro. Antes (28-3-1864), Rocca, Piombino \& Companhia propõe o estudo de uma via-férrea entre Lisboa e Almeida passando por Sintra, Leiria e Coimbra ${ }^{24}$.

O governo parecia acompanhar os desejos dos deputados ao delegar em Sousa Brandão a tarefa de concluir os estudos da linha de Coimbra a Almeida (portaria de 30-8-1864). Crentes nas intenções governamentais, os parlamentares iniciam discussões sobre a sua directriz. Tomás Ribeiro adiantava uma rota pela vertente ocidental da serra da Estrela e Sá da Bandeira definia-a desde a Figueira passando por Coimbra ${ }^{25}$.

Em 1865 um rude golpe nas aspirações destes políticos seria vibrado por Espanha e pelo CSOP. O plano de rede espanhol não incluía o seu prolongamento e o CSOP em consulta sobre linhas internacionais não a considera de primeira ordem, preferindo a ligação pela Beira Baixa,

${ }^{21}$ BMOP. 1862, 1, 43-45.

${ }^{22}$ BMOP. 1865, 9, 287-296.

${ }^{23}$ DL. Sessões da câmara dos deputados de 23-3-1864, 891, 29-3-1864, 939-940, 25-4-1864, 1294, 6-5-1864, 1438-1439, 7-5-1864, 1450-1451 e 9-5-1864, 1475.

${ }^{24}$ AHMOP. CSOP. Livro 19, 361-364.

${ }^{25}$ DL. Sessão da câmara dos Pares de 23-12-1865, 3004-3005 e sessão da câmara dos deputados de 1-2-1865, 305. 
inflexão que se ficava a dever a novos estudos que superavam os obstáculos levantados na década de $50^{26}$.

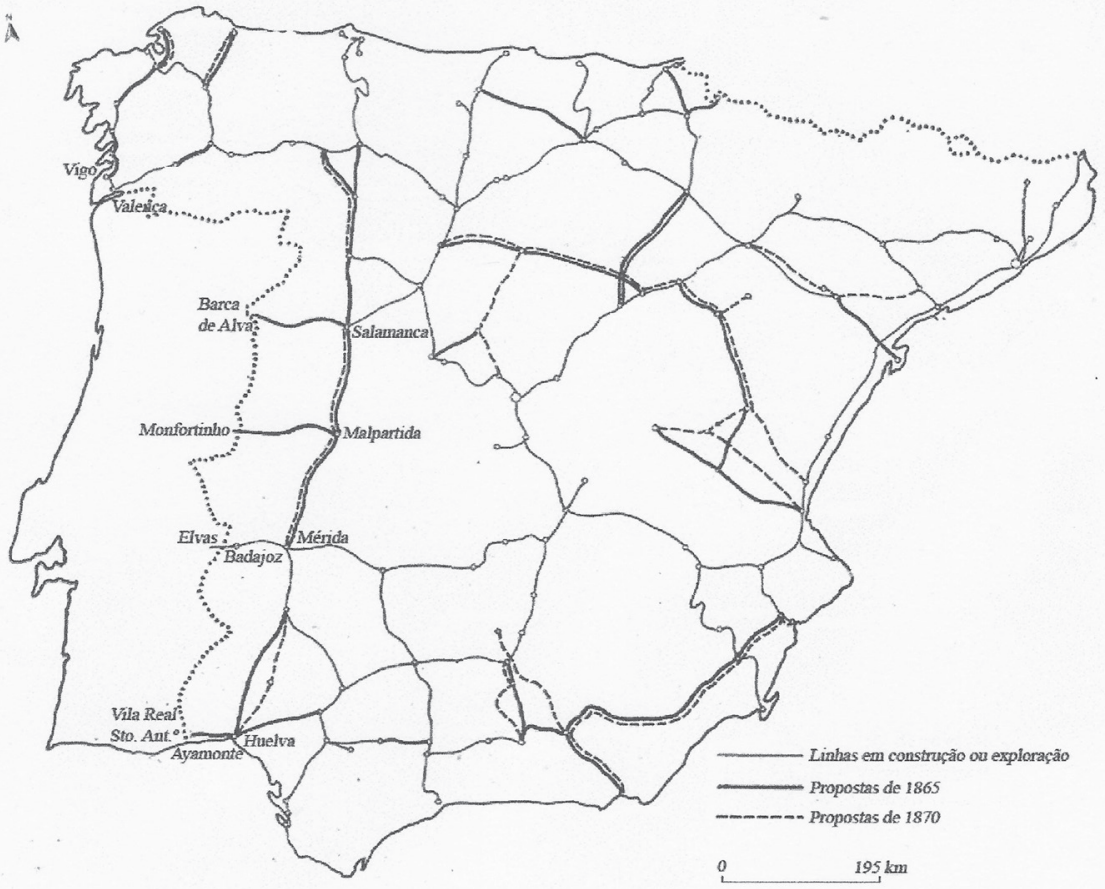

O plano ferroviário de Espanha (1865-1870) $)^{27}$

Animado pelo apoio técnico, o albicastrense Vaz Preto iniciava nos Pares a sua cruzada pela linha da Beira Baixa, mas Sousa Brandão continuava a preferir a via da Beira Alta por Tomar. Um outro engenheiro, o francês radicado em Lisboa Pezerat, alvitrava o início da linha em Coimbra, enquanto que Saldanha a usava para convencer o governo a aceitar o seu Larmanjat ${ }^{28}$.

${ }^{26}$ AHMOP. CSOP. Livro 22, 18-29v. PAGE ALBAREDA, Eusébio - Caminhos de ferro internacionaes em Hespanha. ROPM. 8 (1877), 95, 427 e ss.

${ }^{27}$ ARTOLA, Miguel (dir.) - Los ferrocarriles en España. 1844-1943. Madrid: Banco de España, 1978.

${ }^{28}$ DL. Sessão da câmara dos deputados de 7-5-1867, 1426-1428. BAR. PEZERAT. Pedro José - Memoria sobre dokas commerciaes, bairros maritimos, porto militar sobre a margem direita do Tejo, e caminho de ferro commercial, estrategico e testa dos caminhos de ferro 
Em todo o caso, as duas empresas ferroviárias em Portugal - a Companhia Real dos Caminhos de Ferro Portugueses (CRCFP) e a South Eastern of Portugal - passavam por grandes dificuldades financeiras, de cuja resolução dependia o acesso nacional aos mercados financeiros ${ }^{29}$. O governo regenerador ainda tentou incluir a linha da Beira como contrapartida num acordo para auxiliar a CRCFP, debalde ${ }^{30}$. O plano passou por decretar a construção pelo Estado das linhas do Minho e Douro (lei de 2-7-1867). Ao se assumir como construtor o governo não podia tomar a seu cargo uma linha de grande exigência técnica, pois acreditava-se que só a iniciativa privada o podia fazer, escolhendo linhas cuja construção seria económica. Porém, nos anos seguintes o investimento tornou-se impossível. A necessidade de auxiliar e indemnizar as duas companhias e a subida ao poder dos reformistas obcecados pelas economias traduziu-se numa paralisação da construção.

\section{Qual das Beiras?}

Na década de 70 reúnem-se as condições políticas e económicas para a retoma da construção. $O$ governo regenerador dava preferência à conclusão da linha do Norte (entre Gaia e Porto) e à realização da lei de 2-7-1867, esquecendo a linha da Beira, que seria deixada à iniciativa parlamentar. Em 9-1-1873, um grupo de deputados reformistas da região, chefiados por Luís de Campos, apresenta um projecto de lei decretando a ferrovia entre a linha do Norte e Almeida, argumentando com o interesse da Alemanha que com uma via rápida para Lisboa podia competir com Inglaterra. Semanas depois, outro grande agregado (55 deputados) apresenta (14-3-1873) ideia semelhante propondo duas vias pela Beira Alta e pela Beira Baixa, sendo esta considerada a verdadeira linha internacional, que agradava aos

europeus. Lisboa: Tipografia Franco-Portuguesa, 1867. AHM. APSB. [Carta de Saldanha a Sá da Bandeira sobre o Larmanjat e a Linha da Beira Alta]. Div 3/18/1/3/182.

${ }^{29}$ SAMODÃES, Conde de - Exame retrospectivo dos actos financeiros do ministerio de 22 de Julho de 1868. Porto: Tipografia da Palavra, 1873.

${ }^{30}$ DINIS, Pedro (compil.) - Compilação de diversos documentos relativos à Companhia dos Caminhos de Ferro Portuguezes. Lisboa: Imprensa Nacional, 1915-1919. 4, 132-139. 
interesses castelhanos e que tinha a vantagem de poder servir a Covilhã. Era um projecto maioritariamente regenerador, mas que contou com o apoio de outros partidos. É possível que esta proposta pretendesse apenas calar a insatisfação dos deputados da Beira, relegados que ficaram dos planos do governo. O facto de apenas a comissão de Obras Públicas (e não a de Fazenda) ter sido ouvida e de o projecto não ter sido discutido, apesar de ser possível ao governo pedir ao rei o prolongamento da sessão, o que normalmente era concedido, corrobora a hipótese ${ }^{31}$.

Para a AECP a linha da Beira Baixa era a ideal no caso de os espanhóis também a desejarem, mas a opinião de Madrid tinha-se alterado, daí que a linha da Beira Alta era a única solução possível, restando definir o seu ponto de partida, a margem do Mondego pela qual se espraiaria e a directriz entre Vila Franca das Naves e Espanha ${ }^{32}$. Em todo o caso, portarias de 18-3-1873 incumbem Sousa Brandão e Joaquim de Almeida do estudo de duas linhas desde a estação de Abrantes a Monfortinho e desde Barquinha até Almeida ${ }^{33}$.

A CRCFP não ficou indiferente ao projecto, pois qualquer um dos caminhos-de-ferro entroncava nas suas linhas e em alguma parte do seu traçado eram-lhes paralelos, o que numa interpretação lata do seu contrato lhe poderia dar direito de preferência ou exclusividade. No entanto, só se interessou pela linha da Beira Alta, incumbindo o engenheiro Combelles do seu estudo (30-6-1873), pois a da Beira Baixa concorreria com a de Leste $^{34}$. Combelles apresenta as suas conclusões em Agosto desse ano colocando o início da linha em Mogofores. Até Celorico seguia a directriz já estudada e a partir dali ia por Trancoso, Vila Franca das Naves, Guarda e Almeida ${ }^{35}$. Por seu lado, Sousa Brandão voltara-se para um traçado iniciado na Pampilhosa ${ }^{36}$.

Apesar de o projecto de Combelles ser o melhor, eram necessários mais estudos, conforme requeria a JCOP, mas o governo opta por o aprovar

${ }^{31}$ BAR. Caminhos de ferro. Pareceres parlamentares de 1845 a 1884 [Parecer da comissão de Obras Públicas sobre as linhas da Beira Alta e da Beira Baixa].

${ }^{32}$ AECP - O caminho de ferro da Beira. ROPM. 4 (1873), 38, 47-53. AHMOP. CSOP. Livro 34-A, 81v-84v.

${ }^{33}$ FERNANDES, Liliana Ferreira et al. - Ramal da Lousã. Estudos Sectoriais. 5 (1993).

${ }^{34}$ DINIS, Pedro (compil.) - Compilação..., cit., 5, 271-272 e 282-283.

${ }^{35}$ AHMOP. CSOP. Livro 34-A, 81v-84v e livro 35, 208-218.

${ }^{36}$ VIEIRA, Boaventura José - Caminho de ferro..., cit. 
(portaria de 23-9-1873) 37 e no ano seguinte propõe a sua execução juntamente com as linhas da Beira Baixa e Algarve, prolongamentos de Sueste e ramais de Viseu e Covilhã (21-2-1874). Os pontos iniciais e finais das linhas da Beira ficavam dependentes de novos estudos e de negociações com Espanha. Esta indefinição (para a linha da Beira Baixa nem sequer havia ponto inicial pois Sousa Brandão só entregaria o seu relatório em 7-3-1874 ${ }^{38}$ ) aliada ao carácter megalómano da proposta e ao facto de se prever o pagamento só no final e não ao longo da construção indica alguma demagogia na tentativa de contentar os descontentes (além dos beirões, os algarvios que desde meados da década de 60 viam prometida uma linha até Faro). A sessão legislativa encerraria antes de ser iniciada a discussão, o que era também uma forma de avisar os opositores (sobretudo os reformistas de Viseu na câmara baixa e Vaz Preto entre os Pares) para que não perdessem tempo com oposição a outros projectos. Simultaneamente, mostrava-se aos capitalistas estrangeiros que Portugal estava disposto a investir em mais ferrovias.

Por esta altura há também notícia de uma proposta de Ribeiro de Saraiva, representante de um negociante de vinhos da Bairrada, na companhia de Youle, Beer, Rumball, Whitakers e Knowles, que não se materializou ${ }^{39}$.

Em Março e Novembro de 1874 surgem novos estudos. Sousa Brandão propõe uma linha desde Rossio de Abrantes até às Portas do Ródão, onde atravessava o Tejo em direcção a Castelo Branco e Monfortinho. Os declives não excedentes a $10 \mathrm{~mm} / \mathrm{m}$ e os raios de curva superiores a 500 $\mathrm{m}$ ofereciam excelentes condições de tracção. $\mathrm{O}$ feirense estudaria ainda um ramal até à Covilhã por Castelo Branco ou Idanha $\mathrm{O}$ carácter de ramal era reforçado pelas condições muito modestas em que estava proposto e por se encarar a possibilidade de se construir em bitola (distância entre carris) reduzida ${ }^{40}$. Para o caminho-de-ferro da Beira Alta Boaventura José Vieira sugere o regresso da estação inicial a Coimbra. A linha contornava a cidade até Torres do Mondego, onde entrava na margem direita deste rio. Era uma

${ }^{37}$ TEIXEIRA, Jorge Fernando - Origens, fundação e evolução da CP. Lisboa: CP, 1938.

${ }^{38}$ AHMOP. CSOP. Caixa 18 (1875), parecer 6514 (6-4-1875).

${ }^{39}$ PINHEIRO, Magda - Chemins de fer, structure financiere de l'Etat et dependance éxterieure au Portugal: 1850-1890. Paris: Université de Paris, 1986.

${ }^{40}$ AHMOP. CSOP. Caixa 18, parecer 6514. AHMOP. CSOP. Caixa 18, parecer 6519. 
solução mais barata que a de Mogofores e melhor em termos de tracção que a da Pampilhosa ${ }^{41}$.

Nos inícios de 1875 a JCOP faz uma apreciação global à questão. O início da linha da Beira Alta em Coimbra era elogiado, mas a opção Pampilhosa seria aceitável se melhorada, pois traduzir-se-ia numa construção menos dispendiosa. Uma eventual via paralela à fronteira entre as linhas de Leste e Beira Alta serviria a Covilhã e possibilitaria o seguimento pelo Massueime e pelo Sabor até Trás-os-Montes e Zamora. Já a linha da Beira Baixa poderia ser a correcção da de Leste no que à ligação a Madrid concernia e também a ligação que maior encurtamento para França produziria no caso de em Espanha se construírem os troços de Sória a Castejón e a Pamplona ou de a velocidade média permitida ser superior à da linha da Beira Alta em $4 \mathrm{~km} / \mathrm{h}$. Tudo dependia das condições de tracção. Ora, na linha de Sousa Brandão os declives máximos não ultrapassavam os $10 \mathrm{~mm}$ e os raios das curvas não desciam dos $500 \mathrm{~m}$. Já na linha da Beira Alta aqueles subiam aos $15 \mathrm{~mm}$ e estes desciam aos $300 \mathrm{~m}^{42}$.

Em 9-3-1875 a proposta de 21-2-1874 é renovada e efectivamente discutida sem os prolongamentos de Sueste e com os inícios das linhas fixados em Coimbra e na estação de Abrantes, mas com términos indefinidos (deviam-se ligar aos caminhos-de-ferro de Malpartida e Salamanca). No debate o engenheiro Lourenço de Carvalho, futuro ministro das Obras Públicas, faz eco das considerações da JCOP, reafirmando que a linha da Beira a ser internacional só podia passar pela Beira Baixa ${ }^{43}$. Mesmo assim, os deputados da Beira Alta continuavam a defender os seus campanários, aconselhando jocosamente os colegas a fugirem do vale do Tejo, pois "é arido e triste e pobre como eu não conheço outro tracto de terreno. Abundam, para escurecer o quadro, abutres, que se criam n'aquellas penedias, e no topo do valle está uma povoação, Villa Velha de Rodam, onde (...) as casas ainda não têem vidros!"'44. Na melhor das hipóteses, a linha da Beira Baixa seria exclusivamente nacional, apenas aproveitando

${ }^{41}$ VIEIRA, Boaventura José - Caminho de ferro..., cit.

42 VIEIRA, Boaventura José - Caminho de ferro..., cit. AHMOP. CSOP. Caixa 18. Parecer 6418.

${ }^{43}$ DCD. 16-3-1875, 815-825.

${ }^{44}$ Luís de Campos. DCD. 13-3-1875, 1067. 
um dos ramais de Sousa Brandão ${ }^{45}$. A proposta do governo teria também este intuito: ao não fixar a preferência pela primeira linha a construir (em benefício da simultaneidade de construção), estimulou a discussão entre a oposição, enfraquecendo-a.

Da proposta resulta a nomeação de Almeida de Eça e Sousa Brandão para a elaboração dos projectos definitivos que serviriam de base ao concurso (portaria de 9-4-1875), ambos acompanhados dos militares Alincourt Braga e Bandeira Coelho ${ }^{46}$, mas não a publicação de uma lei, pois a discussão nos Pares foi interrompida pelo encerramento da sessão, o que mostra mais uma vez a pouca vontade do governo em fazer promulgar o diploma.

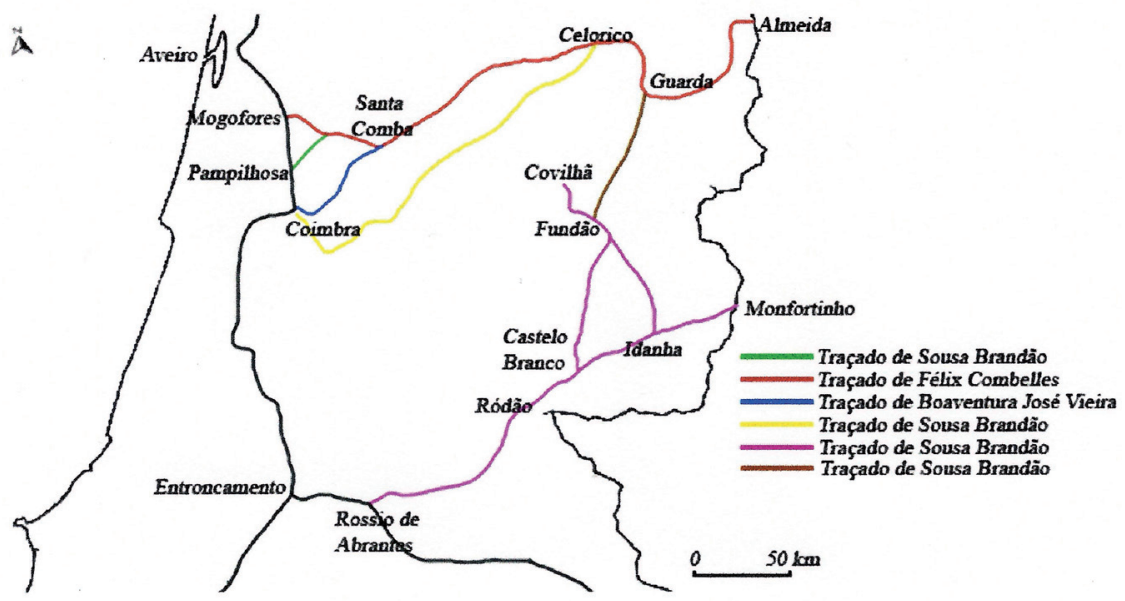

Propostas para linhas na Beira ${ }^{47}$

Demais, só em meados de 1875 o governo enceta conversações com Espanha para a fixação dos pontos de ligação na fronteira ${ }^{48}$. A decisão portuguesa continuava dependente da vontade espanhola, que por lei de 20-9-1870 e pelo plano de 1865 tinha já decretado a linha de Malpartida

${ }^{45}$ DCD. 15-3-1875, 1081-1086.

${ }^{46}$ AHD. Caminhos de ferro..., cit. DINIS, Pedro (compil.) - Compilação..., cit. 5, 460-461.

${ }^{47}$ ROPM. 6 (1875), est. 1.

${ }^{48}$ AHD. Caminhos de ferro de Portugal e Hespanha. Caixa 28 (1055), Maço 23. 
de Plasencia a Portugal ${ }^{49}$. Todavia, das negociações e de novos estudos fronteiriços iniciados em 1875 pelo engenheiro espanhol Page resultou uma nova directriz cruzando a fronteira em Montalvão por Brozas e Alcántara enquanto que do lado português se mantinha a preferência por Monfortinho ${ }^{50}$. $\mathrm{Na}$ lei de 26-1-1876 que finalmente ordenava a construção das linhas da Beira, nada se definiu em relação a este ponto, já que o término da linha da Beira Baixa era o ponto da fronteira de Espanha onde se ligasse a estrada de ferro de Malpartida.

Três dias depois da lei, Sousa Brandão apresenta o seu projecto definitivo. A linha podia começar no Alentejo rumo a Cáceres, no entanto seria meramente uma via de segunda ordem. A sua preferência ia para o traçado desde o Rossio de Abrantes até Ródão e daqui por Idanha e Monfortinho, servindo Castelo Branco e a Covilhã por ramais. Em Abril a JCOP volta a elogiar as excelentes condições de tracção da linha que permitiam aos comboios circular a $40-45 \mathrm{~km} / \mathrm{h}^{51}$.

Uma semana depois de Sousa Brandão, Almeida de Eça apresenta o seu projecto para a linha da Beira Alta com início na Pampilhosa. Era a directriz mais curta, mais barata, que ficava a meio caminho entre Porto e Lisboa, que se prestava melhor a ser continuada até à Figueira, que evitava a duplicação de vias pelo vale do Mondego e que atravessava uma área órfã de comunicações em razoáveis condições de tracção. A ligação de Celorico à fronteira passaria pela Guarda e pelo vale do Noémi. O ponto final da linha era também alterado para Vilar Formoso, o que fez entrar em pânico alguns militares, pelo abandono da praça de Almeida ${ }^{52}$. Em Março, a JCOP concorda com Almeida de Eça, embora reconheça que o início na Pampilhosa pode provocar alguns problemas em termos legais pois a lei previa o início em Coimbra. Uma forma de a contornar seria colocar dupla via até à cidade, o que poderia colocar em vantagem no concurso a CRCFP. A JCOP acaba por

${ }^{49}$ PAGE ALBAREDA, Eusébio - Caminhos..., cit., 425-427.

${ }^{50}$ AHD. Caminhos de ferro..., cit.

${ }^{51}$ BRANDÃO, Francisco de Sousa - Caminho de ferro da Beira Baixa. Relatorio do projecto definitivo. ROPM. 8 (1877), 93, 369-384. AHMOP. CSOP. Livro 37, 27-4-1876.

${ }^{52}$ MACHADO, Joaquim - A praça de Almeida e sua influencia sobre o caminho de ferro da Beira Alta. Revista Militar (RM). 21 (1879), 11, 333-341. EÇA, Fortunato de Almeida de - Caminho de ferro da Beira Alta. Memoria Justificativa. ROPM. 7 (1876), 82-84, 381-399, 409-437 e 447-460 e 8 (1877), 85-86, 44-57 e 61-75. 
aprovar o traçado de Almeida de Eça somente para lá de Santa Comba e o de Boaventura Vieira para cá daquela vila, apesar de admitir que a velocidade média da linha não ultrapassaria os $30 \mathrm{~km} / \mathrm{h}$, o que era aceitável tendo em conta que no caminho-de-ferro do Norte de Espanha a velocidade não ia além $\operatorname{dos} 33 \mathrm{~km} / \mathrm{h}^{53}$, o que à partida condenava a vocação internacional de qualquer linha. Comparativamente em Inglaterra a velocidade média era de $60 \mathrm{~km} / \mathrm{h}$ e tendia a aumentar ${ }^{54}$.

Do lado de Espanha o engenheiro Page tinha concluído em Abril de 1876 que a ligação a Portugal poderia ser feita ao Norte do Tejo. Faltava a anuência da coroa espanhola que estava longe de ser uma realidade, pelo que o governo nacional opta por apenas abrir concurso para a linha da Beira Alta em Maio. De facto em Julho seguinte Espanha concederia a linha de Cáceres a Malpartida e à fronteira portuguesa revelando que mantinha firme a sua intenção de se ligar a Portugal por Montalvão ${ }^{55}$. Portugal não aceitou um traçado um pouco mais extenso e que não merecia a aprovação de Sousa Brandão e optou por prescindir da linha. A solução de nacionalizar a linha da Beira Baixa não se punha, em virtude dos estudos do mesmo engenheiro, embora anos depois (1880) Almeida Pinheiro, no estudo sobre a linha da Beira Baixa entre Praia do Ribatejo e a Guarda, garanta que um comboio vindo de Lisboa chegaria mais rapidamente à fronteira servindo-se desta via do que indo até à Pampilhosa apanhar a linha da Beira $\mathrm{Alta}^{56}$. Por outro lado, a desconfiança em relação às intenções de Espanha de isolar Portugal com uma cintura de ferro não era ainda tão grande ao ponto de o governo ponderar usar dinheiro públicos para construir em Espanha como faria em 1882 com as ligações a Salamanca.

Em 6-5-1876 a AECP sujeita-se à vontade espanhola e no seu primeiro relatório sobre o plano de rede nem coloca em equação a linha pelo vale do Tejo, preferindo a ligação por Castelo de Vide em direç̧ão a Cáceres com um ramal de serviço para a Beira Baixa ${ }^{57}$. Entretanto, o concurso para a

${ }^{53}$ AHMOP. CSOP. Livro 37, 4-3-1876.

${ }^{54}$ ROPM. 13 (1882), 155, 637.

${ }^{55}$ PAGE ALBAREDA, Eusébio - Caminhos..., cit., 425-427.

${ }^{56}$ PINHEIRO, António Almeida - Caminho de ferro da fronteira. ROPM. 15 (1884), $171-172,88$ e ss.

57 AECP. Comissão encarregada de estudar a rede dos caminhos de ferro em Portugal Parecer. ROPM. 9 (1878), 97, 1-8. 
linha da Beira Alta começando em Coimbra (decreto de 20-5-1876) ficaria deserto por nenhum interessado aceitar ser pago no fim das obras. O governo oferece então o pagamento de uma anuidade durante 56 anos, mas a proposta apresentada ao concurso era inaceitável ${ }^{58}$. Face à impossibilidade de contratar uma companhia o governo propõe-se a construir a linha por administração directa desde a Pampilhosa, incluindo um ramal desde a estação de Coimbra até à cidade, mas nada faz por entretanto ter sido substituído ${ }^{59}$.

Apesar de autorizado pelo parlamento e de a linha da Beira Alta ter sido por duas vezes rejeitada no mercado, o governo continuava a não escolher a linha da Beira Baixa, mesmo indo por Montalvão. Além das dificuldades levantadas por Espanha, três outras razões explicam a escolha. Em primeiro lugar a linha da Beira Alta tinha uma maior extensão em Portugal (e atravessava mais círculos eleitorais), critério adoptado desde 1867 pelo então ministro Andrade Corvo ${ }^{60}$, e servia uma zona ainda sem caminhos-de-ferro; segundo, era uma forma de moderar a oposição reformista enraizada em Viseu; terceiro, a CRCFP ainda estava em recuperação da crise do segundo lustro da década de 60 (só a partir de 1877-1878 distribui dividendo ${ }^{61}$ ) e esforçava-se por terminar a ponte Maria Pia pelo que não tinha capacidade para construir uma linha internacional que sangraria a linha de Leste de movimento. Adjudicar a linha a uma outra empresa era impensável por questões contratuais e de interesse económico para a CRCFP, em cuja administração se contavam alguns ministros e parlamentares, mas mais do que beneficiar a companhia estes homens estariam mais preocupados em não a prejudicar, pois todos se lembravam dos apuros por que passara $\mathrm{o}$ Estado à conta dos problemas financeiros da empresa.

${ }^{58}$ FINO, Gaspar (compil.) - Legislação e disposições regulamentares sobre caminhos de ferro. Lisboa: Imprensa Nacional, 1883, 270-282.

${ }^{59}$ DCD. 8-1-1877, 490-491.

${ }^{60}$ DL. Sessão da câmara dos deputados de 25-1-1867, 223-224.

${ }^{61}$ SALGUEIRO, Ângela - A Companhia Real dos Caminhos de Ferro Portugueses. Lisboa: FCSHUNL, 2008, 47-55. TORRES, Amélia - Les investissements français dans les chemins de fer portugais (1850-1900). Paris. Université de Paris IV, 1985, 77. 


\section{A linha da Beira Alta e a Companhia dos Caminhos de Ferro da Beira Alta (CCFBA)}

O governo que sucede aos regeneradores propõe-se a seguir a sua ideia, mas só depois da conclusão das linhas do Minho e Douro ${ }^{62}$. A escolha da Pampilhosa foi motivada por factores financeiros, mas também de oportunidade, pois uns meses antes a JCOP tinha dado parecer positivo (na condição de se alargar a bitola e de se efectuarem melhoramentos nas condições de tracção) a uma linha entra a Figueira e Coimbra concedida a Camille Mangeon e Evaristo Pinto em $1875^{63}$. Pensando que esta linha seria exequível, o governo opta pela Pampilhosa para poupar algum dinheiro sem deixar de ligar Coimbra à Figueira.

No que respeita à linha da Beira Baixa o executivo não só a esqueceu como lhe colocou um empecilho ao atribuir o ramal de Cáceres à CRCFP (decreto de 19-4-1877), mas em tão más condições de tracção que "quando se diga que o caminho de ferro de Lisboa a Madrid tem o celebre ramal de Caceres, e que este caminho é internacional, escusamos de encarecer a sabedoria que tem presidido aos estudos e ás concessões das nossas linhas ferreas" ${ }^{\prime 4}$. Na ânsia de dotar um caminho-de-ferro sem encargos para o Estado, o governo de Ávila (sempre tão crítico do despesismo fontista) concede uma via em más condições mas fácil e barata de fazer (de modo a que a CRCFP a pudesse construir), que era um perigo do ponto de vista militar por abrir o Alentejo a uma invasão ${ }^{65}$ e que parecia tornar obsoleta a linha da Beira Baixa pelo vale do Tejo, que dois meses antes já figurava no relatório final da AECP sobre a rede geral ${ }^{66}$.

O governo sairia antes de fazer aprovar a proposta de construção da linha da Beira Alta e em sua substituição os regeneradores recuperam a

${ }^{62}$ DCD. 23-3-1877, 758-759 e 16-1-1878, 107-108.

${ }^{63}$ AHMOP. CSOP. Livro 37-A, 26-12-1876.

${ }^{64}$ António Augusto de Aguiar. Diário dos Dignos Pares do Reino (DDPR). 8-7-1882, 1124

${ }^{65}$ AHM. António Ribeiro e Eduardo Marrecas Ferreira - Caminhos de Ferro. Reconhecimento da linha do norte de Lisboa ao Porto. Campanha de 1886. Div 3/20/35/1, $8 \mathrm{v}$ e ss.

${ }^{66}$ AECP. Comissão encarregada de estudar a rede dos caminhos de ferro em Portugal Caminhos de ferro em Portugal. Parecer. ROPM. 9 (1878), 100-101, 181-193. 
sua proposta que culmina na lei de 23-3-1878 que previa a administração directa ou a adjudicação. No concurso foi escolhida a Societé Financière de Paris que funda uma companhia subsidiária - a CCFBA - a quem trespassa a construção da linha que se inicia ainda em 1878. A linha da Beira Baixa seria adiada, catalisando a ira de Vaz Preto (e o afastamento do deputado Sousa Lobo da órbita regeneradora) para quem aquele caminho-de-ferro "não se tem feito, porque alem dos quatro poderes do estado marcados pela carta, ha ainda um quinto poder, e esse quinto poder é a companhia dos caminhos de ferro do norte e leste" ${ }^{97}$. A linha da Beira Baixa continuava a ser uma ameaça às linhas fronteiriças da CRCFP sobretudo ao seu novíssimo ramal de Cáceres.

Depressa se começou a pensar em dar um porto à linha da Beira Alta, ligando-a à Figueira, "uma das praias mais frequentadas para uso dos banhos de mar"68. De facto, só como ponto turístico valia, pois como porto comercial nunca suportaria navios de grande calado ${ }^{69}$. Esta ligação fora já proposta por Luís de Lencastre em várias ocasiões ${ }^{70}$, mas não seria concretizada pelos seus amigos regeneradores, mas pelos progressistas, que a pedido da CCFBA outorgam em 1879 a linha desde a Pampilhosa, conseguindo também mostrar algum afastamento em relação à CRCFP, sobretudo quando esta empresa protesta contra a concessão, alegando que a linha em questão era um ramal da linha do Norte. Consultada, a JCOP em 21-8-1879 nega razão à CRCFP que invoca então o paralelismo da linha com a secção entre Alfarelos e Coimbra. Mais uma vez a JCOP (28-8-1879) discorda da CRCFP, mas o governo abre concurso entre as duas companhias, do qual sai vencedora a CCFBA depois de declarar que constrói a linha sem subsídio algum. O governo nomeia então Almeida de Eça para definir a directriz que melhor satisfizesse os interesses nacionais e dos concelhos circundantes. Equacionou-se de novo a hipótese de levar a linha da Pampilhosa a Coimbra e daqui à Figueira o que forçava o pagamento de

${ }^{67}$ DCDPR, 27-3-1878, 200 e 204.

${ }^{68}$ Lourenço de Carvalho. DCD. 20-2-1878, 596.

${ }^{69}$ LOUREIRO, Adolfo - Memoria sobre o Mondego e barra da Figueira. ROPM. 5 (1874), 56-60, 335-356, 391-420, 435-468, 479-510 e 515-545 e 6 (1875), 61-62, 1-28 e 53-94.

${ }^{70}$ DCD. 19-3-1875, 876-877, 20-2-1878, 418 e 13-5-1879, 1689-1690. 
uma indemnização à CCFBA, a abolição de um projecto totalmente gratuito e a escolha de uma linha nefasta em termos de exploração e financeiros e inconveniente para ambas as empresas ${ }^{71}$. A via directa seria aprovada pela JCOP, apesar de as condições de tracção serem menos propícias que no resto da linha ${ }^{72}$. O acordo é vertido em lei (31-3-1880), mas a CRCFP não desistia da sua pretensão e levaria o caso a juízo arbitral, que em 7-8-1880 dá razão à CCFBA encerrando definitivamente a questão ${ }^{73}$. O governo progressista mantinha-se fiel aos seus dogmas de não aumentar a despesa, afrontava a todo-poderosa CRCFP (que durante os governos regeneradores era encarada como um seu morgado ${ }^{74}$ ) e agradava aos deputados regeneradores que tinham sido enjeitados pelo seu próprio partido nesta questão. Em contrapartida, conseguia-se uma linha que no futuro se revelaria inconveniente ${ }^{75}$.

Dois anos depois (1-7-1882) toda a linha é inaugurada ${ }^{76}$, apesar de alguns diferendos entre a CCFBA, a CRCFP (por causa da ligação na Pampilhosa) e sobretudo o governo, os quais só foram resolvidos em 190477. Do lado de Espanha ainda se teve de esperar até ao dia 24-5-1886 para que este caminho-de-ferro se tornasse internacional ${ }^{78}$.

\section{Finalmente, a linha da Beira Baixa}

Em 1880 Almeida Pinheiro é incumbido do estudo de uma linha desde Praia do Ribatejo na linha de Leste até Castelo Branco, Covilhã (directamente ou por ramal) e a linha da Beira Alta. O caminho-de-ferro justificava-se pela Covilhã e por cruzar zonas férteis e produtivas. Seguia pela margem direita do Tejo até às Portas do Ródão antes de inflectir para Castelo Branco,

${ }^{71}$ AHMOP. CSOP. Caixa 23, parecer 8605.

${ }^{72}$ AHMOP. CSOP. Caixa 23, parecer 8886.

${ }^{73}$ DINIS, Pedro (compil.) - Compilação..., cit. 6, 242-251, 255-259 e 295-304. FINO, Gaspar (compil.) - Legislação..., cit. 405-408 e 412-418

${ }^{74}$ Saraiva de Carvalho. DCD. 26-3-1873, 895.

75 PAÇÔ-VIEIRA, Conde de - Caminhos de Ferro Portuguezes. Subsidios para a sua historia. Lisboa: Livraria Clássica, 1905, 289-290.

${ }^{76}$ FINO, Gaspar (compil.) - Legislação..., cit., 431.

77 PAÇÔ-VIEIRA, Conde de - Caminhos ..., cit., 284-289.

${ }^{78}$ EÇA, Fortunato de Almeida de - Caminhos de ferro da Beira Alta. ROPM. 19 (1888), 221-222, 105-162. ALEGRIA, Maria Fernanda - A organização ..., cit., 274-294. 
Covilhã e terminar na linha da Beira Alta. O estudo previa várias hipóteses para a directriz, mas esta era a eleita ${ }^{79}$.

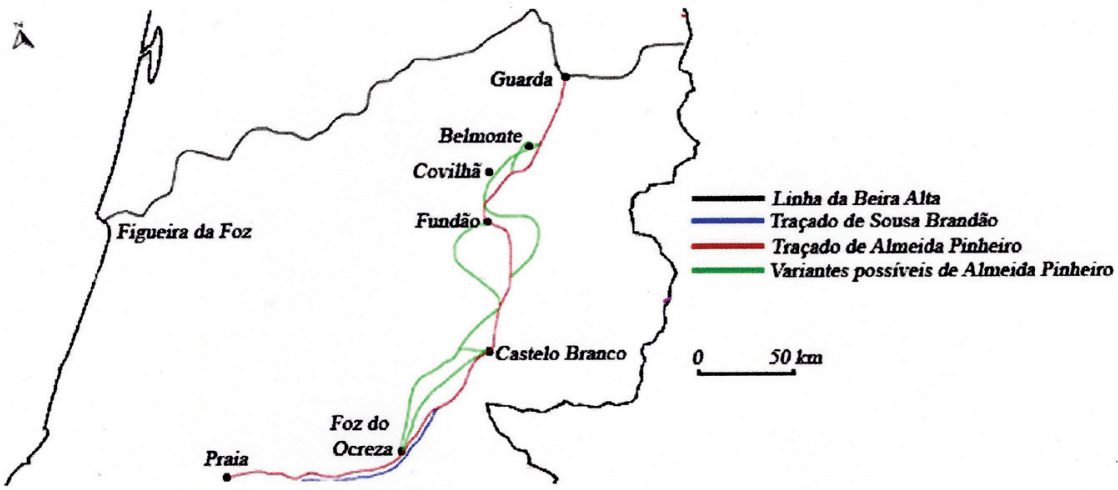

Propostas para a linha da Beira Baixa ${ }^{80}$

Apesar deste projecto e apesar de Cáceres, a JCOP em 9-1-1883 não perdia a esperança de tornar a linha internacional sugerindo a melhoria das condições de tracção até Ródão. Tão grande era o valor que a JCOP atribuía ao seu potencial internacional que até sobre ele emite parecer apesar de tal não lhe ser pedido, o que era algo de muito raro ${ }^{81}$. Tecnicamente, Cáceres não impedia a internacionalização da linha da Beira Baixa e de facto já no século XX a sua ligação a Espanha seria proposta quer no plano de 1929, quer por alguns militares ${ }^{82}$. Quanto ao resto do projecto (que incluía um grande túnel em Alpedrinha e que viria a ser origem de muitos desacordos com a CRCFP) estava também em condições de ser aprovado, sobretudo na aproximação à linha da Beira Alta que se prestava à continuação até à linha do Douro, embora a JCOP preferisse que o seu início se fizesse na estação de Abrantes e não em Praia e que a sua directriz se estendesse pela

${ }^{79}$ PINHEIRO, António Almeida - Caminho de ferro da fronteira..., cit., 62.

${ }^{80}$ ROPM. 15 (1884), est. 2.

${ }^{81}$ AHMOP. CSOP. Caixa 25, parecer 10307.

${ }^{82}$ AHM. Tasso de Miranda Cabral - Conferencia Luso-Hespanhola. Conclusões sobre Ligações a estabelecer entre Portugal e Hespanha. FP 26/11/333/150. PORTUGAL. Ministério do Comércio e Comunicações. Direcção Geral dos Caminhos de Ferro - Plano geral da rêde ferroviária do continente. Lisboa: Imprensa Nacional, 1929. 
margem esquerda do Tejo por ser menos caro, embora menos correcto do ponto de vista militar.

Nesta vertente, e a ter em conta a posição da Comissão de Defesa de Lisboa e seu Porto, a melhor defesa contra a invasão pela Beira Baixa estaria em não alterar a topografia do terreno desde o Baixo Zêzere até Ródão e Abrantes. A fazer-se uma ferrovia esta devia seguir pelo vale do Ocreza e dirigir-se à Guarda ou então seguir sempre pela margem esquerda do Tejo até Ródão. Neste caso em situação de guerra a destruição da ponte poria Lisboa a salvo, embora impedisse o reforço ou a retirada de tropas da Beira Baixa. No entanto acaba por indicar a travessia do Tejo em Abrantes, a construção até Ródão e daqui à Guarda como igualmente útil, pois uma invasão pela Beira Baixa continuava a ser muito pouco provável e igualmente difícil ${ }^{83}$.

Em 19-1-1883 a linha (subsidiada por uma garantia de juro) é proposta por Fontes e Hintze Ribeiro. A lei de 26-4-1883 sanciona o projecto e o concurso é aberto, mas as condições da remissão por parte do Estado afastam os interessados ${ }^{84}$. Posta novamente em praça com esse articulado revisto, licita somente a CRCFP. O contrato é assinado e aprovado pelas câmaras (lei de 26-5-1884) na condição de a CRCFP reformular os seus estatutos no sentido de ter uma maioria de administradores portugueses. Os administradores estrangeiros recusam a pretensão governamental e ameaçam desistir da concessão. Num golpe de teatro, a Assembleia-Geral de 13-9-1884 (que declarou nulas as procurações dos sócios estrangeiros, limitando o voto aos sócios portugueses) rejeitou a decisão da administração e aprovou a reforma dos estatutos, permitindo que o contrato se tornasse definitivo ${ }^{85}$.

Novos estudos de terreno por parte da CRCFP melhoram o traçado em algumas secções e satisfazem às exigências militares, acabando a linha por terminar na Guarda, por servir directamente a Covilhã e por seguir pela margem direita do Tejo logo desde Abrantes ${ }^{86}$. Tudo parecia

${ }^{83}$ AHM. Comissão de Defesa de Lisboa e seu Porto - Parecer sobre o caminho de ferro da Beira Baixa. Div 3/20/38/1.

${ }^{84}$ FINO, Gaspar (compil.) - Legislação..., cit., 527-529 e 581-582.

${ }^{85}$ GOMES, Gilberto - A Linha da Beira Baixa. XXIX Encontro da Associação Portuguesa de História Económica e Social (2009), (web.letras.up.pt/aphes29/data/9th/GilbertoGomes Texto.pdf, consultado em 16.04.2010).

${ }^{86}$ AHMOP. CSOP. Caixa 32, parecer 14169. AHMOP. CSOP. Caixa 32, parecer 14202. 
bem encaminhado até se chegar à serra da Gardunha. Almeida Pinheiro preferia um traçado que incluía um grande túnel de $1 \mathrm{~km}$ furando a serra. Naturalmente, a CRCFP procurou eximir-se desse encargo. Pelo contrato não era obrigada a seguir o projecto de Almeida Pinheiro, mas não o fazendo teria de apresentar alternativas. Se estas fossem rejeitadas duas vezes a CRCFP era obrigada a fazer o que o governo entendesse. A alternativa da CRCFP era melhor em termos de tracção mas era mais extensa o que prejudicava o público (em termos de tarifas) e o governo (eram mais uns quilómetros sobre os quais se garantia um rendimento). De qualquer modo a JCOP acaba por aceitar a solução da CRCFP ${ }^{87}$.

A chegada à Covilhã constituiu outro problema. Para Almeida Pinheiro, levar a linha directamente à cidade era complicado, sendo preferível um ramal, no que era apoiado pela JCOP. Novas sondagens pelo governo e pela CRCFP conseguem aproximar a via o suficiente da Covilhã para evitar a necessidade de uma despesa adicional com um ramal sem infringir os limites das condições de tracção admitidas por lei ${ }^{88}$.

Numa última tentativa de tornar a linha pelo menos parte de uma via internacional a JCOP sugere que a ligação à linha da Beira Alta se faça por meio de uma concordância com entroncamento na Guarda (em direcção à Figueira) e em Vila Fernando (em direcção a Vilar Formoso) ${ }^{89}$.

Os trabalhos foram entregues à Empresa Construtora da Linha da Beira Baixa e começaram em 1887 no troço entre Ródão e Castelo Branco ${ }^{90}$, mas desenvolveram-se muito lentamente, perante um quadro financeiro adverso, conflitos com os empreiteiros e desacordos com o governo quanto à directriz a seguir (em 1888 a JCOP ainda apreciava variantes à linha ${ }^{91}$ ). Tudo isto fez com que a CRCFP acabasse por tomar conta da construção em 1891, gastando muito mais dinheiro do que aquilo que estava a contar e entregando a obra fora do prazo sem a concordância no entroncamento ${ }^{92}$. Em Setembro

${ }^{87}$ FALCÃO, João et al. - Caminho-de-ferro da Beira Baixa. Questão do traçado de Alpedrinha ao Fundão. Lisboa: Tipografia Casa Portuguesa, 1886. AHMOP. CSOP. Caixa 32, parecer 14231.

${ }^{88}$ AHMOP. CSOP. Caixa 33, parecer 14523.

${ }^{89}$ AHMOP. CSOP. Caixa 33, parecer 14711.

${ }^{90}$ AHMOP. CSOP. Caixa 32, parecer 14169.

${ }^{91}$ AHMOP. CSOP. Caixa 34, parecer 15317.

${ }^{92}$ AHMOP. CSOP. Caixa 38, parecer 21692. Caixa 39, parecer 22284. 
de 1891, abre-se à exploração o troço entre Abrantes e Covilhã e em 11-5-1893, o restante percurso até à Guarda ${ }^{93}$.

\section{Conclusão}

No afã de ligar a Nação à Europa escolheu-se a primeira linha que chamou o interesse dos investidores privados e que mereceu a anuência de Espanha, mas que acabaria por não servir os interesses nacionais nem realizar o desejo de fazer de Lisboa o cais da Europa e que uma vez na posse de uma companhia poderosa ainda impediu a construção daquela que era considerada por muitos a verdadeira linha internacional.

A linha de Leste e a linha da Beira Baixa tornaram-se rivais à nascença, mas esta seria filha enjeitada a partir do momento em que a CRCFP perfilha aquela e se vê depois temporariamente incapaz de adoptar mais rebentos da mesma natureza. A indisponibilidade de Espanha em prolongar a linha pretendida pelos portugueses, se bem que real, tornou-se uma desculpa conveniente. Quando finalmente a CRCFP supera essa incapacidade dera já uma pequena irmã à linha de Badajoz e não tinha mais interesse em caminhos-de-ferro internacionais. A linha da Beira Baixa perde assim a sua vocação internacional e assume-se como revitalizadora do centro têxtil da Covilhã, restando saber se realmente o foi ou se ao invés trouxe sobre carris o efeito contrário.

Porém, o País precisava de mais linhas internacionais, sobretudo quando se viu que a linha de Leste não servia. Surgiu então a linha da Beira Alta ligando uma pequena vila (e mais tarde o porto de pesca da Figueira) e indirectamente Lisboa ao grande movimento que se esperava da Europa, que contudo tardou em aparecer: os tráfegos gerados nunca foram apelativos de tal modo que a CCFBA faliu no início do século XX, vivendo a partir daí em concordata com os seus credores ${ }^{94}$. Procurando também servir ao

${ }^{93}$ GOMES, Gilberto - A Linha ..., cit. SALGUEIRO, Ângela - A Companhia ..., cit. 73-76. SILVA, José Ribeiro da e RIBEIRO, Manuel - Os comboios em Portugal. Lisboa: Terramar, 2007, vol. 3, 133-134.

${ }^{94}$ ROPM. 21 (1890), estampa 3. GOMES, Gilberto - A Luz e as Sombras na Gare do Oriente. Lisboa: CP, 1998, 14. 
máximo a zona portuguesa que atravessava, a via adquire contornos de serviço nacional entrando em conflito em termos de velocidade com a sua aptidão internacional. Prova-o o facto de no concurso para atribuição da linha de Alcântara a Sintra (via meramente de segunda ordem e interesse local) proposto no parlamento pelos progressistas se prever que a sua construção e exploração se faria segundo as condições do contrato que deu origem à linha da Beira Alta ${ }^{95}$.

Construída a linha da Beira Alta e decretada a da Beira Baixa, a província parecia fechada no que a caminhos-de-ferro diz respeito quanto mais não fosse pela zona de protecção exclusiva de que gozavam a primeira e a de Leste. Mesmo assim, surgiram propostas para novas linhas cruzando o coração da Beira, uma de Thomas Morton Johnson $1885^{96}$ e outra da Fonseca, Santos \& Viana. Aquela (que previa também ligações às linhas do Norte e Douro) seria rejeitada, esta (prolongando o ramal de Coimbra) seria aceite (alvarás de 10-9-1887 e 8-10-1888) e construída, não por aquela empresa, mas pela CRCFP já no século XX. A Beira, palco de grandes linhas internacionais, recebia agora linhas internas num período em que as ilusões do grande tráfego transfronteiriço se desvaneciam.

\footnotetext{
${ }^{95}$ DCD. 8-1-1881, 27-28.
}

${ }^{96}$ AHMOP. CSOP. Caixa 28, parecer 12219. 